\title{
FTIR-ATR and FT-Raman Spectroscopy for Biochemical Changes in Oral Tissue
}

\section{Magdalena Ligia Naurecka ${ }^{1}$, Bartosz Michał Sierakowski1 ${ }^{1}$, Wiktoria Kasprzycka ${ }^{1}$, Anna Dojs ${ }^{2}$, Michał Dojs ${ }^{2}$, Zbigniew Suszyński ${ }^{3}$, Mirosław Kwaśny ${ }^{1}$}

\author{
${ }^{1}$ Biomedical Engineering Centre, Institute of Optoelectronics, Military University of Technology, Warsaw, Poland \\ ${ }^{2}$ Specialist Periodontal Practice, Gorzów Wielkopolski, Poland \\ ${ }^{3}$ Faculty of Electronics and Computer Sciences, Koszalin University of Technology, Koszalin, Poland \\ Email: *magdalena.naurecka@wat.edu.pl
}

How to cite this paper: Naurecka, M.L., Sierakowski, B.M., Kasprzycka, W., Dojs, A., Dojs, M., Suszyński, Z. and Kwaśny, M. (2017) FTIR-ATR and FT-Raman Spectroscopy for Biochemical Changes in Oral Tissue. American Journal of Analytical Chemistry, 8, 180-188. https://doi.org/10.4236/ajac.2017.83015

Received: January 24, 2017

Accepted: March 3, 2017

Published: March 6, 2017

Copyright (๑) 2017 by authors and Scientific Research Publishing Inc. This work is licensed under the Creative Commons Attribution International License (CC BY 4.0).

http://creativecommons.org/licenses/by/4.0/

\section{cc) (i) Open Access}

\begin{abstract}
Nowadays, biomedicine development is caused by the necessity of fast premalignant and malignant diagnosis. In the case of cancer, it is important to identify degree of tumor's malice. We investigated the differences of Fourier Transform Infrared-Attenuated Total Reflection (FTIR-ATR) and FT-Raman spectroscopy between leukoplakia, oral cancer and normal tissues. Human tissue contains many compounds with known absorption spectra in the range of Near Infrared (NIR) spectroscopy. These compounds have a fingerprint region, which permits their characterization. FTIR spectroscopy is a promising diagnostic tool. There is ability to detect skin, cervix, prostate, breast, esophagus, stomach, bladder and oral cancers [1]. Imaging using FTIR microscope allows analysis of biochemical compounds in microregions of biological materials. FTIR microspectroscopy is the perfect technique for tissues and individual cells analysis [1]. It delivers information about biochemistry of cell or tissue samples and has been applied in many areas of medical research [2]. IR absorption spectra of abnormal tissues and normal tissues are compared by lipid $\left(2800-3000 \mathrm{~cm}^{-1}\right)$, protein $\left(1500-1700 \mathrm{~cm}^{-1}\right)$, and nucleic acids (1000 $1250 \mathrm{~cm}^{-1}$ ) regions [2]. One of the mucous membrane lesions of the mouth is leukoplakia. This change has a "fingerprint region" in the range of $900-1800$ $\mathrm{cm}^{-1}$ [3]. Raman spectroscopy has high potential of medical diagnosis. This method is a molecular specific technique that can be used to develop a fundamental biochemical understanding of tissue physiology and pathology. Both methods are dedicated to screening of preneoplastic and neoplastic tissues and have a potential to reduce morbidity of leucoplakia and oral cancers. Obtained data suggested that these infrared techniques are applicable to biomedical and clinical diagnostics.
\end{abstract}




\section{Keywords}

FTIR-ATR, FT-Raman, Infrared Spectroscopy, Leukoplakia, Oral Cancer

\section{Introduction}

Fourier transform infrared spectroscopy is a vibrational spectroscopy, which based on the absorbance, transmittance or reflection of infrared light. The light is absorbed by sample in different amounts and frequencies, what correspond to the oscillation frequency of the bonds in the tested sample.

Raman spectroscopy is a scattering technique. It is based on Raman Effect-it means that there is difference between frequency of a small fraction of scattered radiation and frequency of monochromatic incident radiation. It is based on the inelastic scattering of incident radiation through its interaction with vibrating molecules [4]. A Raman spectrum contains characteristic peaks that are assigned to a corresponding molecular structure within the illuminated tissue [5].

There are differences between both techniques. Raman is more sensitive to homo-nuclear molecular bonds, while FTIR spectroscopy is more sensitive to hetero-nuclear functional group vibrations and polar bonds. Currently these methods are mainly used in forensic analysis of human fingermarks [6], blood traces [7], and textile dyes [8]. FTIR-ATR spectroscopy allows the objective classification of biological material on a molecular level. Previous studies have shown the potential in categorising cancer and intraepitheilal neoplasia in tissues such as cervix, prostate and gastrointestinal tract [9] [10]. Before determining the type of change by infrared spectroscopy, fluorescent methods are most commonly used. One of these methods' goal is to induce natural fluorophores in tissue and observe abnormal fluorescence patterns [11] [12]. Identification of changes can be made under blue light using e.g. lamp VELscope ${ }^{\triangleright}$ or another with similar wavelength. Abnormalities in autofluorescence can be arisen from a variety of causes. Another method is fluorescence observation after the administration of photosensitive substance called photosensitizer, selectively cumulative in an altered tissue. Photosensitizers, excited appropriate wavelength, visualize areas of accumulation, and at the same time the affected areas [13] [14]. This method is called Photo Diagnosis. Leukoplakia is the most common premalignant or potentially malignant lesion of the oral mucosa [15]. The influence of tobacco habits is the most etiological factor of oral leukoplakia. The histopathology of oral leukoplakia varies widely from beningn to carcinomatous state in situ. It is not possible to determine, based on clinical appearance alone, which areas of leukoplakia are premalignant or malignant. It happens that innocuous clinically lesions may show microscopic evidence of malignant transformation. In this case leukoplakia characterized by a hyperkeratotic thickening of the prickle cell layer of the epithelium, acanthosis, corium infiltration by the plasma cells and cellular atypia [16]. Effective diagnostic methods are very important for early detection and treatment of oral mucosal diseases, especially precancerous 
and cancerous states. The aim of the study is to show the clinical images in white and blue light a pre-malignant and malignant lesion of the oral mucosa. Next comparison with a healthy oral mucosa presents them in spectroscopy analysis.

\section{Materials and Methods}

In this study clinical states of oral mucosa were evaluated with sight in white light and blue (400 - $460 \mathrm{~nm}$ ) light of VELscope ${ }^{\oplus}$ VX or MucoScope ${ }^{\oplus}$ device. Study group consisted of 8 patients ( 3 males and 5 females) suffering from leukoplakia and 3 patients (females) suffering from carcinoma cavum oris. Next the clinically pictures were taken. We took photos in white light with Canon apparatus and through the autofluorescence devices. Chemiluminescence was used as an adjunctive utility to diagnose leukoplakia without replacing biopsy.

The clinical tests were completed with microbiological, histopathological, radiological, USG, CBCT and scintygraphy tests, depending on needs and consultations in other clinical centers. Routine microscopic histopatological examination of biopsy was performed to confirm the diagnosis by Department of Pathomorphology, Provincional Specialist Hospital in GorzówWlkp. Tissue seccions were subjected to spectroscopy. There are shown graphically case of leukoplakia and squamous cell carcinoma on the floor of the mouth and compared with normal oral mucosa using FTIR-ATR and Ramana methods.

\subsection{Tissue Preparation}

Tissue imaging is needed to illustrate physiological and pathological changes which occur in human tissues. They were fixed in $4 \%$ formaldehyde after cut from mouth. Ten- $\mu \mathrm{m}$-thick tissue sections were floated onto reflective slides for FTIR-ATR and FT-Raman spectroscopy. These were de-waxed.

\subsection{FT-Raman Spectroscopy}

A Nicolet iS50 FT-IR spectrometer (Thermo Fisher Scientific) interface with a FT-Raman accessory equipped with $\mathrm{CaF}_{2}$ beam splitter and Indium-GalliumArsenic (InGaAs) detector was used to carry out the measurements. Tissue samples, placed in a glass microscope slides, were illuminated by a $1064 \mathrm{~nm}$ diode laser with a power $50-300 \mathrm{~mW}$ at the sample, and backscattered radiation was collected. The interferograms were averaged over 200 scans for spectra recorded with a resolution of $4 \mathrm{~cm}^{-1}$.

\subsection{FTIR-ATR Spectroscopy}

FTIR-ATR is a method which gives the opportunity to observe absorption of electromagnetic radiation as a result of interaction with the tissue. The measuring range is $400-4000 \mathrm{~cm}^{-1}$. Magnetic interactions are the result of absorption bands (FTIR), which are characteristics for the chemical moieties presented in the sample. Spectra can be obtained from one point or many points what creates surface map of the spectra.

ATR for the biological samples measurements has a diamond crystal. The 
contact crystal-sample surface has about $1 \mathrm{~mm}^{2}$ area.

ATR spectra were recorded using a single reflection golden gate diamond accessory mounted at the Nicolet iN10 FTIR spectrometer (Thermo Fisher Scientific). $\mathrm{KBr}$ beam splitter and MCT detector were used for infrared measurements. The spectra of tissue samples are in the $400-4000 \mathrm{~cm}^{-1}$ range. The spectra are averaging from 128 scans and include atmospheric correction. The spectral resolution was $8 \mathrm{~cm}^{-1}$. The 3D maps are averaging from 81 spectra.

\section{Results and Discussion}

\subsection{Patients and Diagnosis}

Patients with oral cancer (Figure 1), leukoplakia (Figure 2) and normal tissue (Figure 3) presented below.

\subsection{FTIR-ATR Spectroscopy}

FTIR-ATR spectroscopy was used to compare leukoplakia and oral cancer with

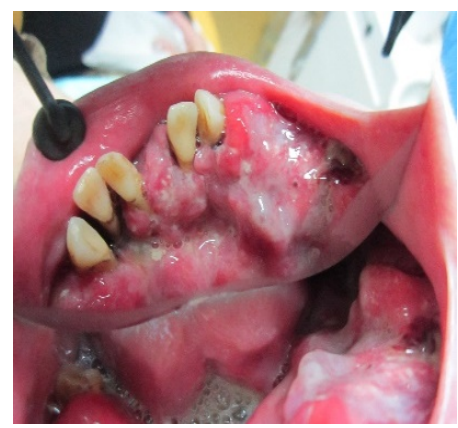

(a)

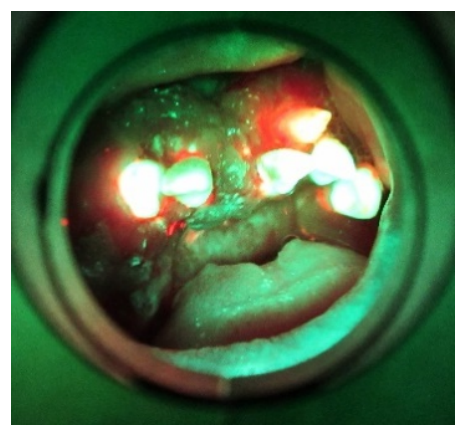

(b)

Figure 1. S.I. Female age 52 squamous cell carcinoma on the floor of the mouth: (a) Optical photo-increasing progression of tumor during 1 year from detection. Tumor in advanced stage includes oral cavity floor. Anterior part of tumor includes lower lip and subcutaneus tissue of chin skin. Tumor cause "swimming tooth" syndrome of 8 teeth in infiltration region. (b) UV photo in VELscope ${ }^{\circledast}$ VX lamp-red colour-bacterial dental plaque and around non-uniformed green color carcinoma tissue.

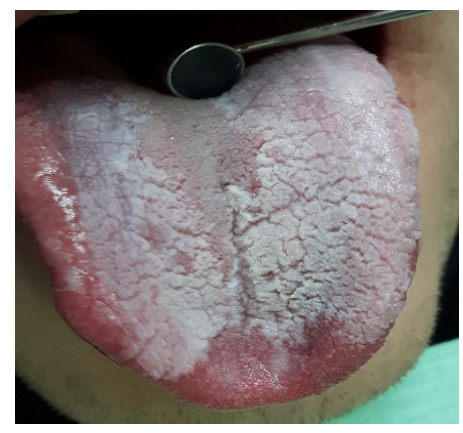

(a)

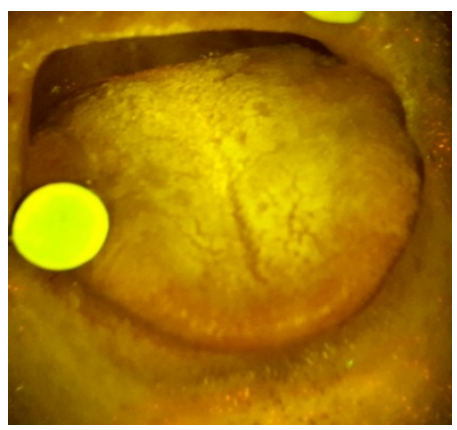

(b)

Figure 2. P.M. Male, age 26 leukoplakia-dorsal tongue surface: (a) Optical photopresence of white coloured patches on dorsal tongue surface. (b) UV photo in MucoScope device with indicator. The area of leukoplakia charakterized by a white hyperkeratotic cell layer surrounded by normal green autofluorescence. 


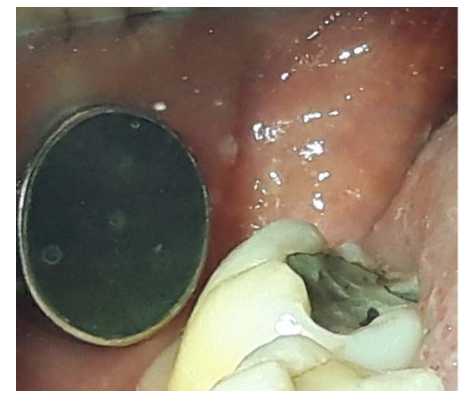

(a)

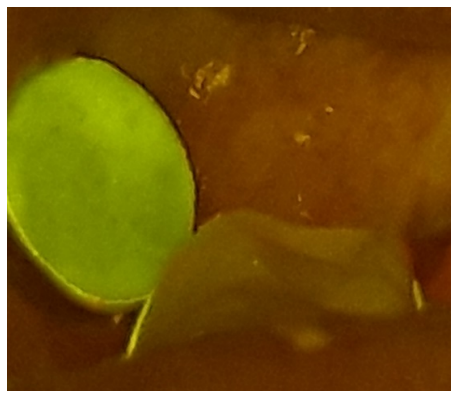

(b)

Figure 3. W.E. female, age 32-control group—retromolar mucosa: (a) Optical photohealthy mucosa, pink, shining and smooth surface. (b) UV photo-reveals pail green, indicatives as a healthy mucosa.

oral normal tissues. Figure 4, Figure 5 presents the spectra from $600-4000$ $\mathrm{cm}^{-1}$. The fingerprint region shows the spectra from $900-1800 \mathrm{~cm}^{-1}$, which is a source of information about specific vibrational modes associated with changes in tissue.

Absorption peak at $1238 \mathrm{~cm}^{-1}$ relates to bands from nucleic acids and is related to symmetrical stretching. Besides the intensities of the phosphate bands, several other differences between normal and cancer tissues are observed in FTIR spectra. These wave numbers are significantly lower than that of normal tissue [17]. The difference in normal, leucoplakia and cancer tissue of band at $1030 \mathrm{~cm}^{-1}$, frequently founds in the glycogen-rich tissue, can be assigned as $-\mathrm{CH}_{2} \mathrm{OH}$ vibrations [18].

\subsection{Raman Spectroscopy}

In Raman spectra there are extra absorption peaks at $1248 \mathrm{~cm}^{-1}$ which relates to $\mathrm{PO}^{2-}$ asymmetric bands [17] and $1320 \mathrm{~cm}^{-1}$ which relates to amide III band components of protein [19] [20] or collagen [21] (Figure 6, Figure 7).

Autofluorescence allows to specifyoral mucosal changes (Figures 1-3) with the naked eye and spectroscopic techniques can identify the degree of these changes (Figures 4-7). At present, clinical diagnostic methods have limitations with in vivo tissue and its biochemical composition. Studies about human tissues use optical techniques such as optical computed tomography, near-UV excitation autofluorescence, FTIR [22] and Raman spectroscopy which are still progressing. Noninvasive FTIR and FT-Raman spectroscopy is the way of the future to study leukoplakia and oral cancer tissue. These optical techniques do not need pre-treatment or labelling to characterize tissue in real-time [23]. Infrared and Raman spectroscopy is applied to the analysis of human tissues, the spectra of complex composition such as lipids, protein, nucleic acid [17].

Many researchers report that sugar chains have association with malignant transformation. Some kinds of sugar chains play an important role in uncontrolled cell growth tumors, tumor invasion and metastasis [17] [24]. Glycogen is the storage form of glucose in cell and is essential for energy supply and glucose homeostasis [25]. Strong peak at C-O stretching and C-O banding from glycogen 


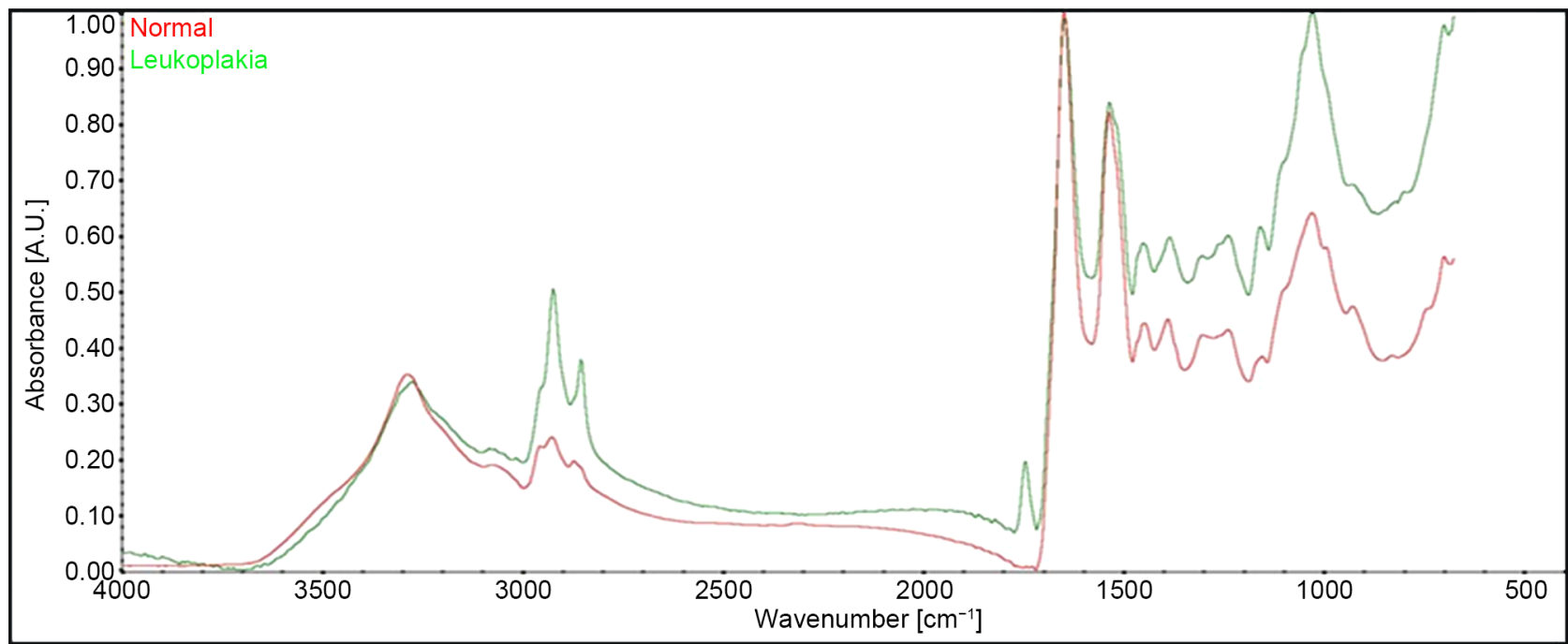

Figure 4. The FTIR-ATR spectrum of leukoplakia (green line) and normal (red line) tissue.

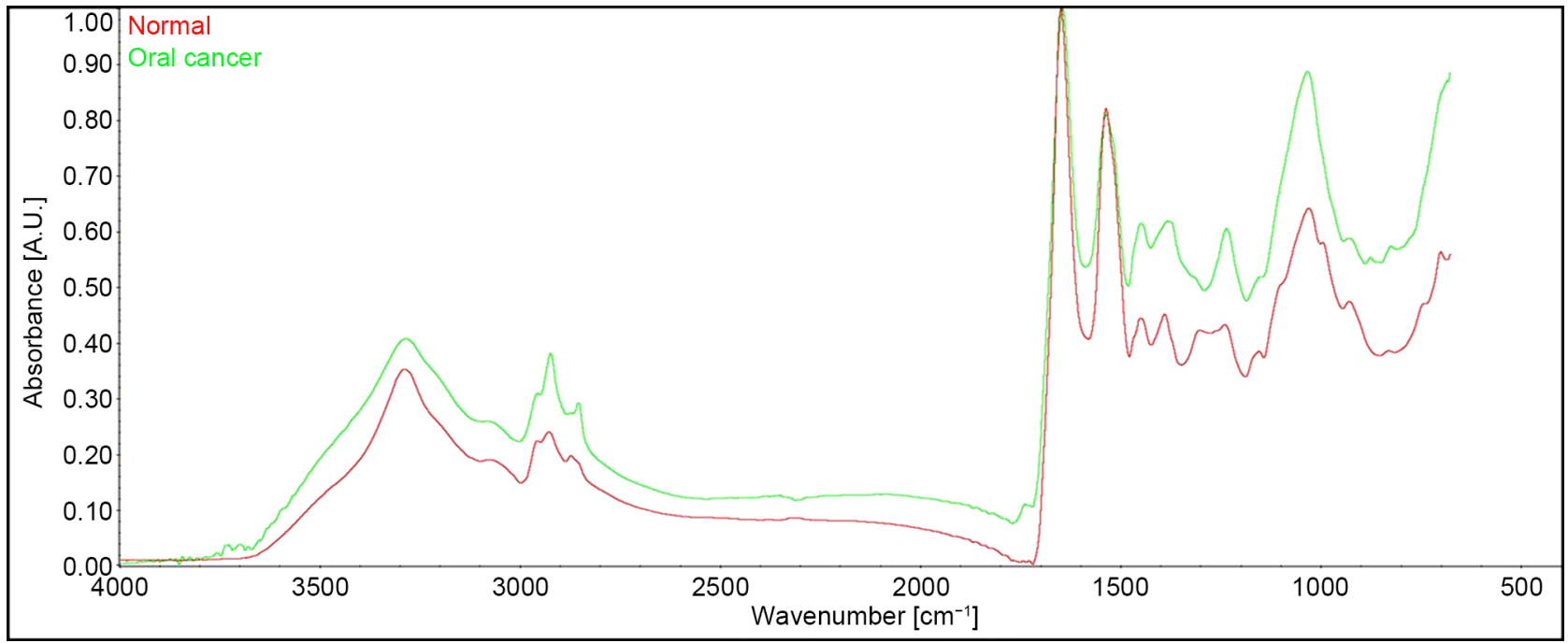

Figure 5. The FTIR-ATR spectrum of oral cancer (green line) and normal (red line) tissue.

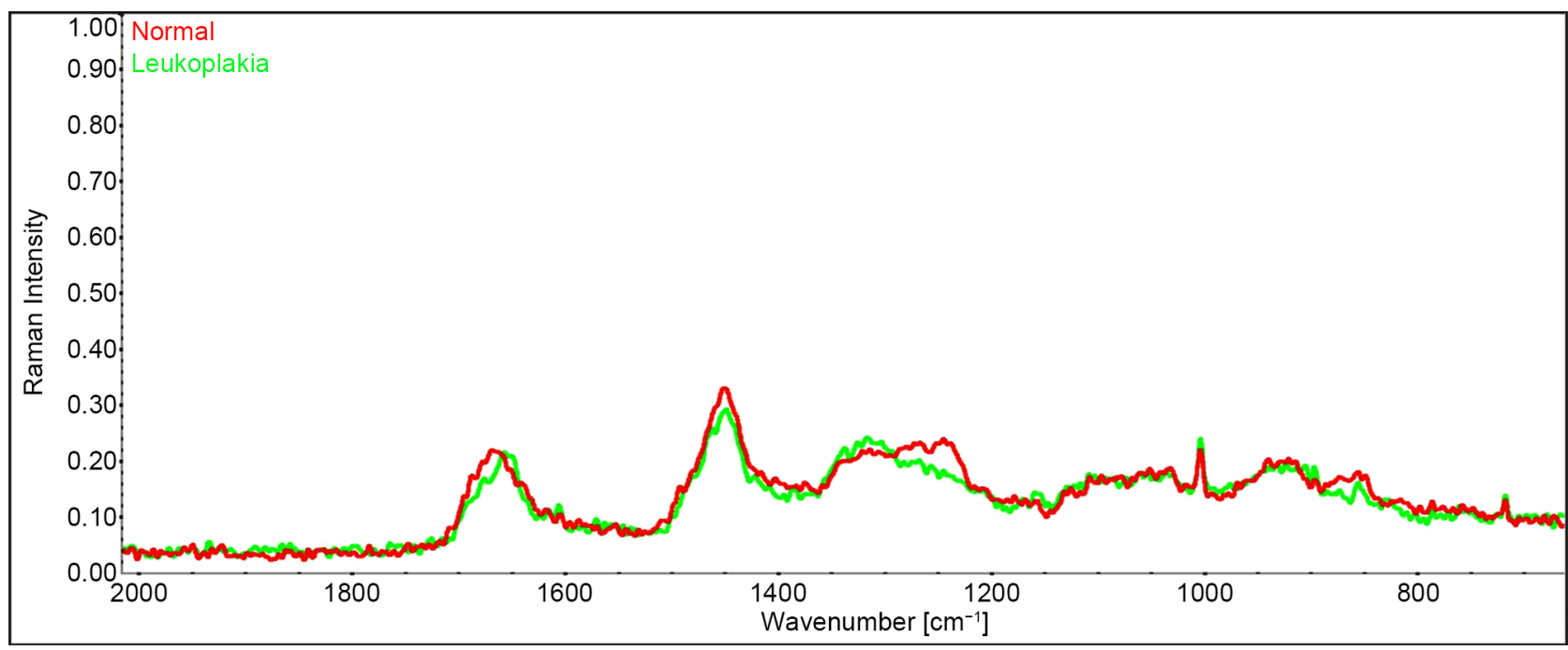

Figure 6. FT-Raman spectra of normal (red line) and leukoplakia (green line) tissue. 


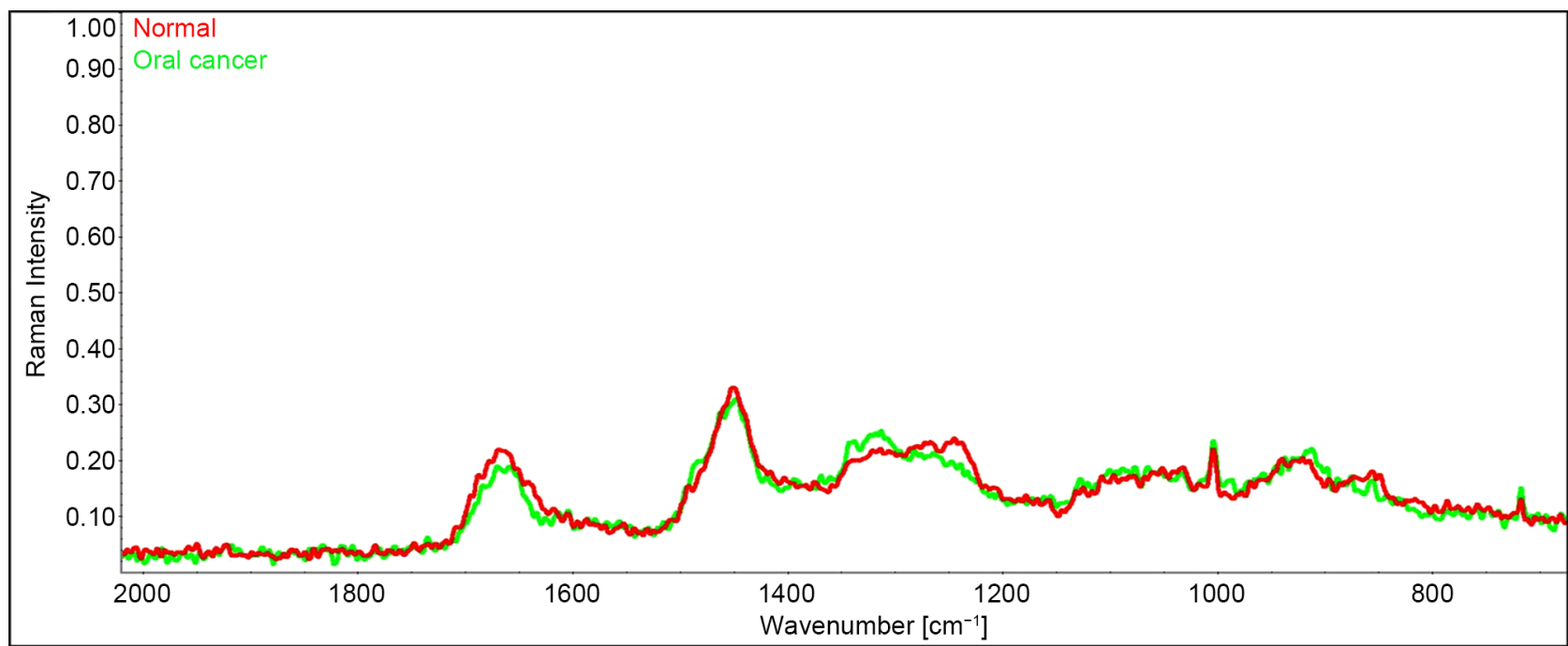

Figure 7. FT-Raman spectra of normal (red line) and oral cancer (green line) tissue.

Table 1. The compounds characteristic for leukoplakia tissue.

\begin{tabular}{cccc}
\hline \multicolumn{2}{c}{ Peak position $\left(\mathrm{cm}^{-1}\right)$} & Vibrational mode & $\begin{array}{c}\text { Proposed } \\
\text { primary source }\end{array}$ \\
\cline { 1 - 2 } Leukoplakia tissue & Cancer/normal tissue & & glycogen \\
1024 & 1030 & C-O streching, C-O bending & nucleic acid \\
1238 & 1238 & $\mathrm{PO}_{2}$-stretching & protein \\
1388 & $1388 / 1390$ & $\mathrm{CH}_{2}$ bending & protein \\
1454 & 1451 & $\mathrm{CH}_{2}$ bending & protein \\
1650 & 1535 & amide II: CN-H, C-N & protein \\
\hline
\end{tabular}

are positioned at $1030 \mathrm{~cm}^{-1}$ (Table 1). $\mathrm{PO}_{2}^{-}$binding derived from nucleic acids. This indicates an increased metabolism of cancer cells. Vibration molecular bonds at $1238 \mathrm{~cm}^{-1}$ may be offset by $10 \mathrm{~cm}^{-1}$ and marked in Raman spectrum at $1248 \mathrm{~cm}^{-1}$.

\section{Conclusion}

In conclusion, our data suggested that FTIR and FT-Raman techniques are potentially applicable to clinical diagnostics change in oral as well as basic analyses at the molecular level. Leukoplakia is an ordinary premalignant condition. It is known that quick detection and screening for oral neoplasia are the best way to reduce mortality of disease. However, method of screening has not been defined successfully. Accurate visualization of VELscope ${ }^{\circledast} \mathrm{VX}$ and similar type devices is limited. FTIR and FT-Raman spectroscopy could give the easiest, fastest and most accurate diagnosis. These complementary techniques can be used in biomedicine to assess the effectiveness of photodynamic therapy. 5-aminolevulinic acid (ALA) is one of the photosensitizers used in the treatment of lesions of the 
oral greasy. Further studies with FTIR and Raman techniques must be taken to ensure their efficiency and repeatability.

\section{References}

[1] Szczerbowska-Boruchowska, M. (2012) Mikrospektroskopia w podczerwieni z transformacją Fouriera w diagnostycemedycznej.

[2] Zohdi, V., Whelan, D.R., Wood, B.R., Pearson, J.T., Bambary, K.R. and Black, M.J. (2015) Importance of Tissue Preparation Methods in FTIR Micro-Scepctroscopical Analysis of Biological Tissues: Traps for New Users. PLOS ONE, 10, e0116491. https://doi.org/10.1371/journal.pone.0116491

[3] Benerjee, S., Chatterjee, S., Anura, A., Chakrabatry, J., Pal, M., Ghosh, B., Paul, R.R., Sheet, D. and Chatterjee, J. (2016) Global Spectral and Local Molecular Connects for Optical Coherence Tomography Features to Classify Oral Lesions towards Unravelling Quantitative Imaging Biomarkers. RSC Advances, 6, 7511-7520. https://doi.org/10.1039/C5RA24117K

[4] Settle, F.A. (1997) Handbook of Instrumental Techniques for Analytical Chemistry. Prentice Hall, Upper Saddle River, 55-56.

[5] Cals, F.L.J., Koljenovic, S., Hardillo, J.A., Baatenburg de Jong, R.J., Bakker Schut, T.C. and Puppels, G.J. (2016) Development and Validation of Raman Spectroscopic Classification Models to Discriminate Tongue Squamous Cell Carcinoma from NonTumorous Tissue. Oral Oncology, 60, 41-47. https://doi.org/10.1016/j.oraloncology.2016.06.012

[6] Wei, Q., Zhang, M., Ogorevc, B. and Zhang, X. (2016) Recent Advances in the Chemical Imaging of Human Fingermarks: A Review. Analyst, 141, 6172-6189. https://doi.org/10.1039/C6AN01121G

[7] McLaughlin, G., Doty, K.C. and Lednev, I.K. (2014) Discrimination of Human and Animal Blood Traces via Raman Spectroscopy. Forensic Science International, 238, 91-95. https://doi.org/10.1016/j.forsciint.2014.02.027

[8] Groves, E., Palenik, C.S. and Palenik, S. (2016) A Survey of Extraction Solvents in the Forensic Analysis of Textile Dyes. Forensic Science International, 268, 139-144. https://doi.org/10.1016/j.forsciint.2016.03.043

[9] Mackanos, M.A. and Contag, C.H. (2010) Fiber-Optic Probes Enable Cancer Detection with Ftir Spectroscopy. Trends Biotechnology, 28, 317-323. https://doi.org/10.1016/j.tibtech.2010.04.001

[10] Taylor, S.E., Cheung, K.T., Patel, I.I., Trevisan, J., Stringfellow, H.F., Ashton, K.M., Wood, N.J., Keating, P.J., Martin-Hirsch, P.L. and Martin, F.L. (2011) Infrared Spectroscopy with Multivariate Analysis to Interrogate Endometrial Tissue: A Novel and Objective Diagnostic Approach. British Journal of Cancer, 104, 790-797. https://doi.org/10.1038/sj.bjc.6606094

[11] Richards-Kortum, R.R. and Sevick-Muraca, E. (1996) Quantitative Optical Spectroscopy for Tissue Diagnosis. Annual Review of Physical Chemistry, 47, 555-606. https://doi.org/10.1146/annurev.physchem.47.1.555

[12] Ramanujam, N. (2000) Fluorescence Spectroscopy of Neoplastic and Nonneoplastic Tissues. Neoplasia, 2, 89-117. https://doi.org/10.1038/sj.neo.7900077

[13] Vicente, M.G.H. (2001) Porphyrin-Based Sensitizers in the Detection and Treatment of Cancer: Recent Progress. Current Medicinal Chemistry-Anti-Cancer Agents, 1, 175-194. https://doi.org/10.2174/1568011013354769

[14] Roswell Park Cancer Institute. Photodynamic Therapy Using HPPH in Treating Patients with Recurrent Dysplasia, Carcinoma in Situ, or Stage I Oral Cavity Cancer. 
National Library of Medicine, Bethesda. http://clinicaltrials.gov/show/NCT00670397

[15] Kramer, I.R., Lucas, R.B., Pindborg, J.J. and Sobin, L.H. (1978) Definition of Leukoplakia and Relted Lesions: An Aid to Studies on Oral Precancer. Oral Surgery, Oral Medicine, Oral Pathology, Oral Radiology, 46, 518-539. https://doi.org/10.1016/0030-4220(78)90383-3

[16] Krawczyk-Krupka, A., Waśkowska, J., Raczkowska-Siostrzonek, A., KościarzGrzesiok, A., Kwiatek, S., Straszak, D., Latos, W., Koszowski, R. and Sieroń, A. (2012) Comparision of Cryotherapy and Photodynamic Therapy in Treatment of Oral Leukoplakia. Photodiagnosis and Photodynamic Therapy, 9, 148-155. https://doi.org/10.1016/j.pdpdt.2011.12.007

[17] Fukuyama, Y., Yoshida, S., Yanagisawa, S. and Shimizu, M. (1999) A Study on the Differences between Oral Squamous Cell Carcinomas and Normal Oral Mucosas Measured by Fourier Transform Infrared Spectroscopy. Biospectroscopy, 5, 117 126. https://doi.org/10.1002/(SICI)1520-6343(1999)5:2<117::AID-BSPY5>3.0.CO;2-K

[18] Wang, H.P., Wang, H.C. and Huang, Y.J. (1997) Microscopic FTIR Studies of Lung Cancer Cells in Pleural Fluid. The Science of the Total Environment, 204, 283-287. https://doi.org/10.1016/S0048-9697(97)00180-0

[19] Yang, Y., Sulé-Suso, J., Sockalingum, G.D., Kegelaer, G., Manfait, M. and El Haj, A.J. (2005) Study of Tumor Cell Invasion by Fourier Transform Infrared Microspectroscopy. Biopolymers, 78, 311-317. https://doi.org/10.1002/bip.20297

[20] Fujioka, N., Morimoto, Y., Arai, T. and Kikuchi, M. (2004) Discrimination between Normal and Malignant Human Gastric Tissues by Fourier Transform Infrared Spectroscopy. Cancer Detection and Prevention, 28, 32-36. https://doi.org/10.1016/j.cdp.2003.11.004

[21] Fung, M.F.K., Senterman, M.K., Mikhael, N.Z., Lacelle, S. and Wong, P.T.T. (1996) Pressure-Tuning Fourier Transform Infrared Spectroscopic Study of Carcinogenesis in Human Endometrium. Bispectroscopy, 2, 155-165. https://doi.org/10.1002/(SICI)1520-6343(1996)2:3<155::AID-BSPY2>3.3.CO;2-F

[22] Wong, P.T.T., Wong, R.K. and Fung, M.F.K. (1993) Pressure-Tuning FT-IR Study of Human Cervical Tissues. Applied Spectroscopy, 47, 1058-1063. https://doi.org/10.1366/0003702934415291

[23] Puppeis, G.J., de Mul, F.F. Otto, C., Greve, J, Robert-Nicoud, M. and Arndt-Jovin, D.J. (1990) Study Single Living Cells and Chromosomes by Confocal Raman Microspectroscopy. Nature, 347, 301-303. https://doi.org/10.1038/347301a0

[24] Mjiyad, N.E., Caro-Maldonado, A., Remirez-Peinado, S. and Munoz-Pinedo, C. (2011) Sugar-Free Approaches to Cancer Cell Killing. Oncogene, 30, 253-264. https://doi.org/10.1038/onc.2010.466

[25] Zois, C.E. and Harris, A.L. (2016), Glycogen Metabolism Has a Key Role in the Cancer Microenvironment and Provides New Targets for Cancer Therapy. Journal of Molecular Medicine, 94, 137-154. https://doi.org/10.1007/s00109-015-1377-9 
Submit or recommend next manuscript to SCIRP and we will provide best service for you:

Accepting pre-submission inquiries through Email, Facebook, LinkedIn, Twitter, etc. A wide selection of journals (inclusive of 9 subjects, more than 200 journals)

Providing 24-hour high-quality service

User-friendly online submission system

Fair and swift peer-review system

Efficient typesetting and proofreading procedure

Display of the result of downloads and visits, as well as the number of cited articles Maximum dissemination of your research work

Submit your manuscript at: http://papersubmission.scirp.org/

Or contact ajac@scirp.org 